\title{
Morphology of the lingual papillae in the chimpanzee
}

\author{
By \\ Shoichi EMURA \\ Heisei College of Health Sciences, Gifu 501-1131, Japan \\ - Received for Publication, September 7, 2017-
}

\begin{abstract}
Key Words: chimpanzee, lingual papillae, scanning electron microscopy
Summary: We microscopically examined the dorsal lingual surface of an adult chimpanzee (Pan troglodytes). The tongue of the chimpanzee was about $13 \mathrm{~cm}$ long. Filiform papillae were distributed over the entire dorsal surface of the lingual body. There were many fungiform papillae scattered among the filiform papillae. At the posterior end of the lingual body, a triangular arrangement of the vallate papillae, with the apex of the triangle directed posteriorly, was observed. The filiform papillae on the lingual apex consisted of a main papilla and secondary papillae. The filiform papillae on the lingual body had several pointed processes. There were dome-shaped fungiform papillae scattered among the filiform papillae. The vallate papillae were surrounded by grooves and were flattened-oval shaped. Many foliate papillae were observed on the posterolateral regions of the tongue.
\end{abstract}

Many studies have reported on the structures of the lingual surfaces of various animals. In the order Primates, there have been a few studies of the tongues of monkeys (Kubota and Hayama, 1964; Arvidson, 1976; Iwasaki et al., 1988; Emura et al., 2002). Such studies have revealed variations in the morphology and distribution of papillae on the dorsal lingual surface among these species.

However, no scanning electron microscopic (SEM) studies of the tongue of the chimpanzee have been carried out. The purpose of this study is, therefore, to examine three-dimensionally the dorsal lingual surface and the connective tissue core of the chimpanzee, in order to compare the results with those of previous reports on other mammals.

\section{Materials and Methods}

The tongue of one adult chimpanzee of the family Hominidae was used in this study. The tongue was fixed in $10 \%$ formalin. Small blocks containing papillae were cut with a razor blade and post-fixed with $1 \%$ osmium tetroxide for $1 \mathrm{~h}$. Thereafter, the specimens were dehydrated through a graded series of acetone exchange fluids and critical-point-dried. To examine the three-dimensional connective tissue structure of the lamina propria of the mucosa, some of the samples were washed in distilled water after fixation and macerated in $3.5 \mathrm{~N} \mathrm{HCl}$ at $35^{\circ} \mathrm{C}$ for $3 \mathrm{~d}$. After maceration, the tissues were washed in distilled water, post-fixed in $1 \%$ osmium tetroxide for $1 \mathrm{~h}$, and dehydrated in a series of acetone exchange fluids and critical-point-dried. All specimens were sputtered with Pt-Pd before examination by SEM (Hitachi S-3500N, Tokyo, Japan) at an accelerating voltage of $10 \mathrm{kV}$.

\section{Results}

Macroscopically, the tongue of the chimpanzee was about $13 \mathrm{~cm}$ long. Filiform papillae were distributed over the entire dorsal surface of the lingual body (Fig. 1). There were fungiform papillae scattered among the filiform papillae (Fig.1). At the posterior end of the lingual body, a triangular arrangement of the vallate papillae, with the apex of the triangle directed posteriorly, was observed (Fig. 1).

SEM analysis revealed that the filiform papillae on the lingual apex consisted of a main papilla and secondary papillae (Fig. 2a). The filiform papillae on the lingual body had several pointed processes (Fig. 2c). There were dome-shaped fungiform papillae scattered among the filiform papillae (Fig. 2a,c). The connective tissue cores of those filiform papillae consisted of processes of various 


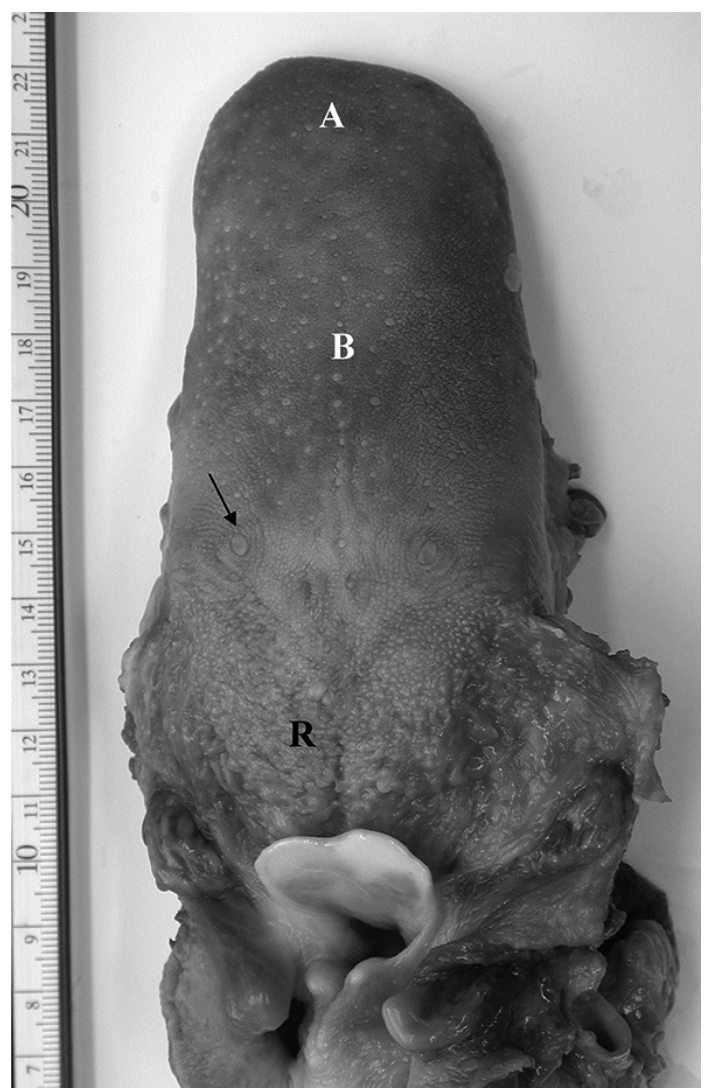

Fig. 1. Macrograph of a chimpanzee tongue. $\mathrm{A}=$ lingual apex. $\mathrm{B}=$ lingual body. $\mathrm{R}=$ lingual root. Arrow = vallate papillae.

size, while these of the fungiform papillae had several ditches (Fig. 2b, d). The vallate papillae were surrounded by grooves and were flattened-oval shaped (Fig. 3a). The connective tissue cores of the vallate papillae were covered with numerous small spines (Fig. 3b). Many foliate papillae were observed on the posterolateral regions of the tongue (Fig. 3c). After removing epithelium from the foliate papillae many small spines became apparent (Fig. $3 \mathrm{~d})$.

\section{Discussion}

Kullaa-Mikkonen and Sorvari (1985) reported that filiform papillae of the human tongue consisted of two parts: the body and hairs, and each filiform papilla had 6-10 hairs. Iwasaki et al. (1988) reported that the filiform papillae were distributed over the entire dorsal surface of the squirrel monkey tongue except for the lingual radix zone, and a flattened circular area was located in the center of the filiform papillae, and was encircled by several pointed processes. Furthermore, the structure of the filiform papillae was almost identical in any area of the dorsal surfaces
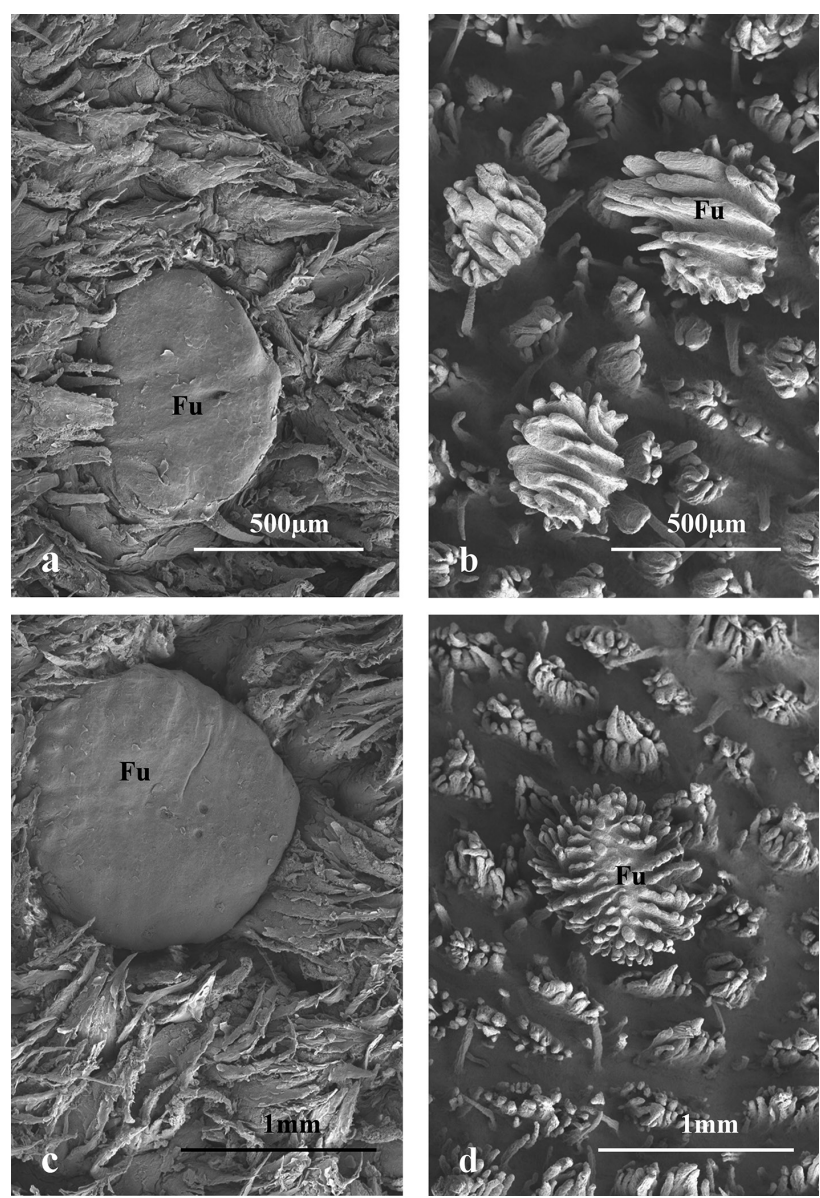

Fig. 2. (a) The filiform papilla on the lingual apex has a main papilla and secondary papillae. (c) The filiform papillae on the lingual body has several pointed processes. $(\mathrm{a}, \mathrm{c}$ ) There are dome-shaped fungiform papillae scattered among the filiform papillae. (b, d) The connective tissue cores of those filiform papillae consist of processes of various size, while these of the fungiform papillae has several ditches. $\mathrm{Fu}=$ fungiform papilla.

of the tongue. Iwasaki et al. (1992) reported that filiform papillae of the Japanese monkey, which were densely distributed all over the dorsal surface of the lingual body, were crown-shaped, with a central, circular area that sloped in the anterior direction and several branches that surrounded it in a semicircle from the back of the central area. Emura et al. (2002) reported that the filiform papillae of the lingual apex of the savanna monkey had a conical shape, and that of the lingual body had a filiform papilla with several pointed processes. In this study, the filiform papillae on the lingual apex consisted of a main papilla and secondary papillae. The filiform papillae on the lingual body had several pointed processes.

Krause and Cutts (1982) reported that the foliate papillae in the opossum were not observed, and that elongated mucosal folds with numerous, irregular, finger-like projections were present on the posterolateral borders where 

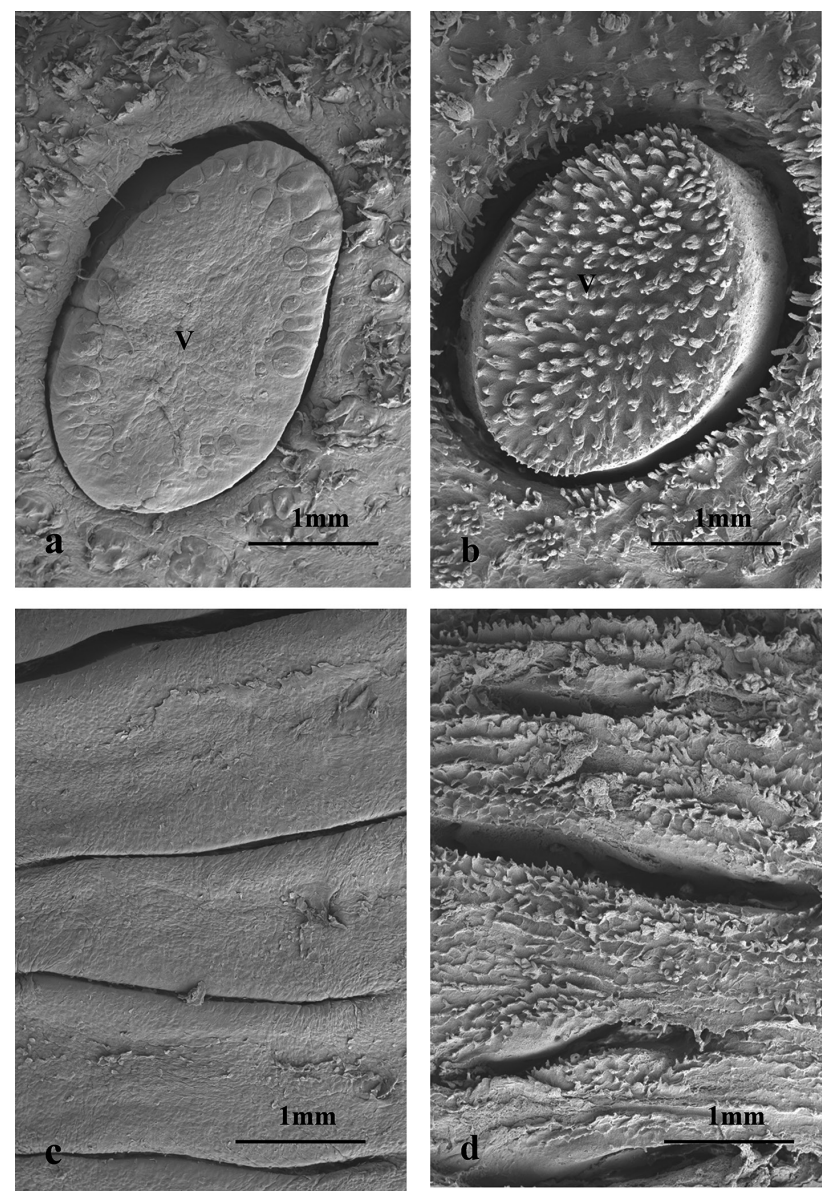

Fig. 3. (a, b) The vallate papillae are surrounded by grooves and were flattened-oval shaped. The connective tissue core of the vallate papillae is covered with numerous small spines. (c, d) Many foliate papillae were observed on the posterolateral regions of the tongue. After removing epithelium from the foliate papillae many small spines become apparent. $\mathrm{V}=$ vallate papilla.

the foliate papillae were normally found in other species. In this study, the foliate papillae, which had some ridges separated by deep grooves, were found on the posterolateral aspect of the posterior part of the tongue. This result was the same as that observed in the flying squirrel and nutria (Emura et al., 1999, 2001).

Many studies have described the three-dimensional structure of the vallate papillae in the mammalian tongue. In particular, several studies have shown that the vallate papillae are flattened and oval in shape and are surrounded by a groove and a pad (Krause and Cutts, 1982; Chamorro et al., 1986; Qayyum et al., 1988; Chunhabundit et al., 1992; Agungpriyono et al., 1995; Atoji et al., 1998; Emura et al., 2013). The vallate papillae of the cat, dog, and flying squirrel have been found to be encircled by filiform papillae in the posterior body (Boshell et al., 1982; Iwasaki and Sakata, 1985; Emura et al., 1999).
Equine vallate papillae are composed of a primary papilla that is divided into several secondary papillae by intermediate grooves (Chamorro et al., 1986). Occasionally, in bovine vallate papillae, twin papillae are surrounded only by a primary papillary groove (Chamorro et al., 1986). The vallate papillae of the bush dog are surrounded by a groove and a crescent pad, and on the dorsal surfaces of these papillae, small conical papillae have been observed. In addition, some vallate papillae of the Asian black bear have been shown to be composed of primary papillae that are divided into several secondary papillae by intermediate grooves (Emura et al., 2001).

The lingual papillae of the chimpanzee tongue resemble that of the Japanese monkey than those of the human.

\section{Acknowledgements}

I am grateful to the staff of Tennouji Zoo for supplying the specimen.

\section{References}

1) Arvidoson K: Scanning electron microscopy of fungiform papillae on the tongue of man monkey. Acta Otolaryngol 1976; 81:496502.

2) Atoji Y, Yamamoto Y, Suzuki Y: Morphology of the tongue of a male Formosan serow (Capricornis crispus swinhoei). Anat Histo1 Embryol 1998; 27:17-19.

3) Agungpriyono S, Yamada J, Kitamura N, Nisa C, Sigit K, Yamamoto Y: Morphology of the dorsal lingual papillae in the lesser mouse deer, Tragulus javanicus. J Anat 1995; 187:635-640.

4) Boshell JL, Wilborn WH, Singh BB: Filiform papillae of cat tongue. Acta Anat 1982; 114:97-105.

5) Chamorro CA, de Paz P, Snadval J, Fernandez JG: Comparative scanning electron-microscopic study of the lingual papillae in two species of domestic mammals (Equus caballus and Bos Taurus). I. Gustatory papillae. Acta Anat 1986; 125:83-87.

6) Chunhabundit P, Thongpila S, Somana R: SEM study on the dorsal lingual surface of the common tree shrew, Tupaia glis. Acta Anat 1992; 143:253-257.

7) Emura S, Hayakawa D, Chen H, Shoumura S: Morphology of the dorsal lingual papillae in the newborn panther and Asian black bear. Okajimas Folia Anat Jpn 2001; 78:173-178.

8) Emura S, Hayakawa D, Chen H, Shoumura S: Morphology of the dorsal lingual papillae in the Japanese macaque and savanna monkey. Anat Histol Embryol 2002; 31:313-316.

9) Emura S, Okumura T, Chen H: Morphology of the lingual papillae in the jaguar. Okajimas Folia Anat Jpn 2013; 89:93-97.

10) Emura S, Tamada A, Hayakawa $D$, Chen H, Jamali M, Taguchi H, Shoumura S: SEM study on the dorsal lingual surface of the flying squirrel, Petaurista leucogenys. Ann Anat 1999; 181:495-498.

11) Emura S, Tamada A, Hayakawa D, Chen H, Shoumura S: SEM study on the dorsal lingual surface of the nutria, Myocastor coypus (in Japanese). Acta Anat Nippon 2001; 76:233-238.

12) Iwasaki S, Miyata K, Kobayashi K: Scanning-electron-microscopic study of the dorsal lingual surface of the squirrel monkey. Acta Anat 1988; 132:225-229.

13) Iwasaki S, Sakata K: Scanning electron microscopy of the lingual dorsal surface of the beagle dog. Okajimas Folia Anat Jpn 1985: 62:1-14. 
14) Iwasaki S, Yshizawa H, Suzuki K: Fine structure of the dorsal lingual epithelium of the Japanese monkey Macaca fuscata fuscata. Acta Anat 1992; 144:267-277.

15) Krause WJ, Cutts JH: Morphological observations on the papillae of the opossum tongue. Acta Anat 1982; 113:159-168.

16) Kubota K, Hayama S: Comparative anatomical and neurohistological observations on the tongues of pigmy and common marmosets. Anat Rec 1964; 150:473-486.
17) Kullaa-Mikkonen A, Sorvari TE: A scanning electron microscopic study of the dorsal surface of the human tongue. Acta Anat 1985; 123:114-120.

18) Qayyum MA, Fatani JA, Mohajir AM: Scanning electron microscopic study of the lingual papillae of the one humped camel, Camelus dromedaries. J Anat 1988; 160:21-26. 